\title{
Na trama discursiva de uma antologia de ensaios sobre o Brasil: consituição, formulação e circulação de sentidos em Nenhum Brasil existe: pequena enciclopédia
}

\author{
Luciana Cristina Ferreira DIAS * \\ UNICAMP/ UNICENTRO
}

Resumo: Considerando a problemática acerca da identidade nacional nos estudos de perspectiva discursiva (PÊCHEUX, 1990; ORLANDI, 1999), este trabalho busca refletir sobre uma coleção de ensaios Nenbum Brasil existe, de João Cezar Rocha (2003), estabelecendo, assim, conexões entre os três processos de produção da linguagem na antologia: sua constituição (memória discursiva, interdiscurso), formulação (textualização da antologia) e seus modos de circulação na sociedade. Neste caso, examinamos a relação entre a materialidade linguística e discursiva no domínio da formulação e circulação quando estávamos confrontados com a organização dessas coleções, considerando as implicações das antologias no trabalho de leitura em língua materna.

Palavras-Chave: Discurso; Texto; Construção da identidade brasileira.

\footnotetext{
Abstract: Taking into account the issue of national identity from a discursive perspective (Pêcheux, 1990; Orlandi, 1999), this paper aims to reflect upon the essays collection Nenbum Brasil existe (João Cezar Rocha, 2003), establishing connections among three

* Doutora em Linguística Aplicada pela Unicamp e professora assistente na área de Língua Portuguesa, na Universidade Estadual do Centro-Oeste (Guarapuava-PR). Contato: diaslucian@yahoo.com.
} 
processes of language production in the anthology: its constitution (memory discourse, interdiscourse), formulation (textualization of anthology) and the ways of circulation in the society. In this case, we examined the relationship between linguistic and discursive materiality in the domain of formulation and circulation when faced with the organization of these collections, considering the implications of using anthologies when working with reading in the mother tongue.

Key-words: Discourse; Text; Brazilian identity construction.

\section{Introdução}

Este estudo parte de uma preocupação com a construção de sentidos sobre a identidade nacional brasileira, tomando-se como base o espaço da discursividade de uma antologia de ensaios de múltiplos autores que apresenta uma especificidade: o fato de ter sido produzida inicialmente nos Estados Unidos e publicada no Brasil três anos depois, por ocasião da Comemoração dos 500 anos do Brasil, a coleção de ensaios Nenbum Brasil existe: pequena enciclopédia.

Ancorado na Análise do discurso de linha francesa (PÊCHEUX, 1998; 1990; ORLANDI, 1999; 2001; SERRANI, 1993; ZOPPI-FONTANA, $2007^{1}$ ), o trabalho volta seu olhar para

\footnotetext{
${ }^{1}$ Ressalto aqui a leitura inspiradora do texto En los márgenes del texto, intervalos de sentidos en movimiento (2007), de autoria da professora Dra. Mônica Zoppi-Fontana. Este texto, no qual ela se dedica à análise do funcionamento enunciativo-discursivo da obra de Calvino Marcovaldo ovvero, le stagioni in città, em termos de imagens de leitor e de leitura, foi extremamente relevante, proveitoso e fundamental para que enfrentasse o desafio de compreender, no caso do meu objeto de estudo, os meandros dos lugares enunciativos no espaço antológico e assim pudesse me aprofundar, em termos analíticos, tanto no efeito-autor quanto no efeitoleitor que a antologia põe em funcionamento em suas várias partes: notas, ensaios introdutórios, prefácios, seções, orelhas, posfácios.
} 
um tipo específico de produção de conhecimentos, dentro da esfera acadêmico-intelectual: a produção de antologias ou volumes de ensaios. ${ }^{2}$ Assim sendo, a ordem do discurso da ensaística brasileira se revelou como superfície de emergência (FOUCAULT, 1969) que mereceria olhar especial, quer pela ausência de estudos que focalizem esse gênero de uma perspectiva discursiva, quer pelo trabalho de interpretação que se produz por autores que buscam entender o Brasil.

Em termos de estruturação, o artigo se divide em duas partes. Na primeira parte, apresentamos um panorama geral do campo da análise do discurso e alguns conceitos-chave para este estudo. $\mathrm{Na}$ segunda parte, analisamos o gesto de nomear a antologia, seus elementos paratextuais (notas da editora, agradecimentos, orelha da obra e ensaio introdutório), de modo que buscamos levantar as representações de sentidos dominantes sobre o Brasil e seu povo a fim de relacionar tais representações com questões de identidade cultural (cf. SERRANI, 2006, p. 98). Neste movimento de trazer para cena a construção de sentidos dominantes dessa coleção de textos, contemplamos uma reflexão sobre a relação que se coloca entre as coleções de ensaios e o processo de leitura deste tipo de obra.

\section{Análise do Discurso: Pressupostos Teóricos}

Vale dizer que este trabalho insere-se no quadro teórico da Análise do discurso desenvolvida na França a partir de 1960, que teve em Michel Pêcheux seu maior representante. Este campo contribuiu para garantir uma especificidade ao trabalho analítico acerca das antologias a partir da consideração de uma interdependência entre materialidade linguística (a estrutura da coleção, seu formato, seu aspecto físico) e o interdiscurso, que,

\footnotetext{
${ }^{2} \mathrm{O}$ trabalho ora apresentado é parte das discussões desenvolvidas na tese de doutorado Embates, debates de sentidos sobre o Brasil em antologias de ensaios: identidade, memória e leitura.
} 
por sua vez, está estreitamente ligado à noção de memória discursiva. Em outras palavras, na confluência dos eixos intra e interdiscursivo (PÊCHEUX, 1998), buscamos examinar na ordem do texto, isto é, da horizontalidade da cadeia (intradiscurso) a rede complexa de Formações discursivas em que todo dizer está inserido

Mostra-se necessário evidenciar que memória, para a Análise de Discurso, não diz respeito à memória psicológica. Memória não significa depósito de conteúdo homogêneo, mas, como diz Pêcheux, trata-se de "um espaço móvel de divisões, de disjunções, de deslocamentos e de retomadas, de conflitos de regularização... um espaço de desdobramentos, réplicas, polêmicas e contradiscursos" (PÊCHEUX, 1999, p. 56).

Apoiado numa visão de antologia enquanto construção discursiva que se ancora num eixo norteador (um pano de fundo, um tema sobre o qual ela se fundamenta), o estudo tem como objetivo compreender em que medida um material desta natureza pode projetar um imaginário de leitura marcado pelas condições de produção e pelas formações imaginárias presentes no texto- as imagens que os interlocutores fazem de si e dos outros e a imagem que fazem do objeto discursivo.

Partimos da premissa de que a memória histórico-cultural do país ganha corpo na textualidade (cf. ORLANDI, 2001), na formulação dos sentidos que constituem a textura dessas coleções. Outro autor que também nos inspirou na análise dessas discursividades é Foucault (1969, p. 141). A partir das discussões propostas por esse autor, interessa-nos compreender o campo de elementos antecedentes em relação aos quais a antologia, como conjunto de enunciados, se situa, aquilo que constitui seu passado, a define, mas que tem o poder de reorganizá-la, redesenhando aquilo o que a torna possível, segundo relações novas.

Também é válido pensar, com base em Pêcheux (1990), que o sujeito, para a $\mathrm{AD}$, tem que ser visto como ser social e ideologicamente constituído. Assim, é interessante questionar uma concepção de sujeito intencional, fonte de seu dizer.

Dessa forma, entende-se que a $\mathrm{AD}$ não trabalha com uma visão de sujeito que encontraria na linguagem um instrumento, 
mas um espaço de um sujeito afetado pela ideologia e constituído pelo inconsciente. Temos neste caso os dois esquecimentos dos quais falou Pêcheux. O primeiro esquecimento refere-se à ilusão de o sujeito ser fonte e origem do dizer, quando apenas retoma sentidos preexistentes. Poderíamos problematizar a questão da leitura centrada no texto enquanto produto fechado e acabado. $\mathrm{Na}$ visão discursiva, é preciso se ater às relações de sentidos que se estabelecem entre um texto e outros - existentes, possíveis, imaginários. No caso do segundo esquecimento, referente à ilusão do sentido único, questionamos a problemática da unicidade de sentido. Para AD, é preciso considerar que de um lado o sentido pode ser outro, e de outro, o sujeito não tem controle pleno dos sentidos.

2 Nenhum Brasil Existe: Pequena Enciclopédia: Um Imaginário Discursivo Produzido pela Antologia

Nenhum Brasil existe: Pequena Enciclopédia é um projeto de organização de ensaios sobre o Brasil que fora inicialmente publicado em língua inglesa, contendo sessenta e cinco ensaios críticos sobre o Brasil. Naquele primeiro momento, nos Estados Unidos, o volume veio à luz como um número especial da revista Portuguese Literacy and Culture Studies com o título Brazil 2001: A Revisionary History of Brazilian Literature and Culture (História Revista da Cultura e Literatura Brasileira).

A edição brasileira, por sua vez, sob o título de Nenbum Brasil existe foi publicada em 2003 e contou com mais 23 ensaios. Tal edição, lançada pela Topsbooks Editora, constitui um novo processo de formulação e circulação da obra, tanto pelo título de caráter irônico e polêmico quanto pela inscrição de novos textos e a inclusão de nova seção de ensaios chamada Audiovisual.

Considerando as especificidades das condições de produção da antologia, Nenbum Brasil existe surgiu em meio a uma busca do empreendimento antológico em traduzir para a língua portuguesa um volume que já fora publicado em língua inglesa (panorama da Literatura Brasileira), durante as comemorações dos 500 anos do 
Brasil ocorridas nos Estados Unidos dentre as quais se deu o lançamento de tal trabalho, na biblioteca do Congresso, em Washington, a partir da articulação de autores brasileiros e estrangeiros.

Voltando o olhar para a construção discursiva da antologia e também para as imagens de leitor e de obra (antológica) construída na obra, buscamos compreender em que medida uma coleção de ensaios se projeta como um guia de leitura, produzindo um efeito de buscar democratizar a leitura e ampliar as reflexões em torno dos dilemas nacionais.

Tendo-se em vista a textualidade do título, notas, agradecimentos, orelhas e ensaio introdutório, a categoria analítica escolhida para este estudo está associada à noção de ressonância discursiva, desenvolvida por Serrani-Infante (1993) a partir da concepção de paráfrase de Pêcheux. A noção de ressonância discursiva diz respeito ao exame de fatos linguístico-discursivos que se repetem e participam da produção de representação de sentidos predominantes. Em nosso caso, serão observadas as repetições no nível da formulação de itens lexicais da mesma família ou de raízes lexicais diferentes, construções sintáticas que se relacionam parafrasticamente, os modos de dizer presentes no discurso, ou seja, voltamos o foco para aquilo que ressoa (repete) e representa os lugares que o organizador da coleção atribui a si mesmo ou ainda a imagem que ele tem do referente (Brasil, sua cultura e literatura), além das imagens do que seja antologia, leitor e leitura construídas pela obra.

\subsection{Análise dos elementos paratextuais da antologia Nenhum Brasil existe}

Em termos de análise, buscamos examinar a macro-estrutura da antologia (SERRANI, 2006) a partir do estudo tanto do título da coleção (gestos de nomear a antologia) quanto das partes, dos ensaios introdutórios, dos posfácios, de notas bibliográficas e dos apêndices. 
Segundo Guimarães (2000), ao nomear ocorre um acontecimento discursivo, que é resultado de um recorte no interdiscurso. O nome funciona a partir de uma história de enunciações, de tal maneira que a ideologia do sujeito nomeador está presente no nome escolhido.

A respeito de Nenbum Brasil existe, é válido considerar o jogo entre o primeiro gesto de nomear a antologia, em língua inglesa, Portuguese Literacy and Culture Studies com o título Brazil 2001: A Revisionary History of Brazilian Literature and Culture (História Revisionária da Cultura e Literatura Brasileira e o título em língua portuguesa Nenbum Brasil existe.

Tendo como base Nenbum Brasil existe, pode-se dizer que há distintos modos de leitura deste material, dependendo das condições de produção de leitura: leitura descompromissada, trabalho intelectual, pesquisa, aprofundamento crítico, leitura escolar-acadêmica. No processo de leitura, para AD, não há "um" sentido no texto que o leitor deva "captar". Ou seja, o sentido não é apreendido no texto; é o leitor quem atribui sentido para o texto (cf. ORLANDI, 1988). Assim, a leitura é produzida visto que $o$ sentido não está no texto, mas na relação autor e leitor

$\mathrm{Na}$ versão inglesa $A$ Revisionary History of Brazilian Literature and Culture (História Revisionária da Cultura e Literatura Brasileira), a palavra revisão ressoa explicitamente na antologia produzida em língua inglesa. Os sentidos, de que a antologia se refere a uma maneira de esboçar um panorama àquele que tem interesse sobre o país, apontam para um leitor que deseja conhecer o Brasil. As representações imaginárias de leitor deste material relacionam-se ao estrangeiro, interessado na cultura brasileira.

Já o título em língua portuguesa, esse é carregado de historicidade. Nenbum Brasil existe revela um trabalho com a alteridade (com a voz de Drummond, já que a construção nenhum Brasil existe é parte de um poema do autor) e um trabalho com a memória de país vazio e ausente. Para os leitores brasileiros, a antologia convoca a crítica e a polêmica, projetando a imagem de leitores imaginados como estudantes de ensino médio e universitários, ávidos por leituras críticas. 
Se o título da coleção produz seus efeitos, o mesmo pode ser dito para a capa, as notas, a orelhas, as epígrafes e os comentários postos à margem do texto, que também podem ser classificados de acordo com a terminologia de Genette (1997) de paratextos, o que se relaciona a um espaço múltiplo e disperso de textos que compõem o todo da obra.

SD (1) Nenhum Brasil existe- Pequena enciclopédia almeja apresentar ao leitor um importante conjunto de ensaios sobre a formação da cultura brasileira, enfeixando reflexões de renomados intelectuais sobre os dilemas e perspectivas futuras da sociedade nacional (orelha da obra).

SD (2) Deve-se, sobretudo, destacar o alto nivel dos colaboradores deste volume, todos eles reconhecidos intelectuais e professores de diversas instituições do Brasil e do exterior. Praticamente a totalidade dos textos foi escrita especialmente para este volume, e se pode afirmar, com segurança, que a primeira vez que se reíne um grupo de colaboradores de tal qualidade (orelha da obra).

SD (3) Com a publicação de Nenhum Brasil existe Pequena enciclopédia, a Topbooks, a UNIVERCIDADE e a UERJ colocam à disposição do público o melhor da pesquisa acadêmica dedicada à compreensão da cultura brasileira (orelha da obra).

Neste caso, o locutor-organizador, na figura de Rocha, destaca, na seção intitulada Agradecimentos, no início da antologia, o reconhecimento do trabalho relevante de instituições para a emergência da obra. Há que considerar que uma nota, seja de agradecimento, seja de apresentação, muitas vezes, é vista ingenuamente como mera ilustração do que a coleção de ensaios pretende ser. Contudo, a partir de um exame dessas seções iniciais, nota-se que o peso e a ênfase da antologia recaem nos sentidos positivos da coleção, ou seja, a obra se projeta como agrupamento de bons textos, produzindo um efeito positivo em relação a si mesma. Isso pode ser notado pela repetição de construções: 
importante conjunto, renomados intelectuais, alto nivel dos colaboradores, grupo de colaboradores de tal qualidade, melhor da pesquisa acadêmica.

SD (4) De igual forma, o leitor interessado na formação da sociedade brasileira encontrará em suas páginas um guia seguro para compreender a história cultural do país, pois os ensaios especialmente preparados para esta obra combinam a profundidade do enfoque com a elegância na apresentação dos temas discutidos (orelha da obra).

SD (5) Com tal cuidado editorial, pretende-se transformar este livro numa obra de referência indispensável para estudantes universitários e mesmo para alunos do Ensino médio que estejam se preparando para ingressar na universidade (orelha da obra).

Ademais, a antologia emerge com uma função de fornecer aos leitores (brasileiros) um espaço de leitura marcado pela insistência em promover o conhecimento, a compreensão sobre o Brasil e sua formação, na medida em que este leitor das antologias é constituído a partir da imagem de um vazio, de um desconhecimento ou de uma ausência de práticas de leitura críticoreflexiva. Um leitor que precisa ser preenchido pela leitura da antologia ou despertado para a crítica e/ou questionamento. A leitura apresenta-se a partir da antologia como atividade de compreensão e conhecimento da história cultural do país. Assim, a própria antologia quer ocupar este lugar de "obra de referência" para estudantes.

\subsection{Análise do ensaio introdutório}

O texto que abre a antologia, assinado por João Cezar Rocha, organizador da obra, responsável pelo controle da dispersão de texto, está sendo tomado aqui como um paratexto, na medida em que se trata de um texto que contextualiza a antologia Nenbum Brasil existe. Contudo, além desse caráter de falar da obra e apresentála ao leitor, em termos de tema e de seções de ensaios, há que se levar em conta uma linha muito tênue entre a paratextualidade e 
metatextualidade, visto que o ensaio assinado por Rocha também, ao explicar a contraditória formulação nenhum Brasil existe, comenta outros textos, a partir da análise crítica. Neste sentido, é válido compreender que este texto traz a voz do ensaístaorganizador, ancorada em meio ao arranjo de outras vozes, a partir de uma imagem de especialista em Literatura Brasileira, situado em um contexto de produção intelectual.

O ensaio introdutório funciona como um discurso paralelo e suplementar (ORLANDI, 1990, p. 116) em relação ao conjunto de textos da antologia. Com efeito, como discursividade que apresenta e justifica a emergência da obra, o ensaio introdutório intervém no interdiscurso, atualizando sentidos, propondo, nas palavras de Orlandi (1990) um gesto "que vai além da simples documentação; através da documentação (pela citação de outros discursos), ele propõe, na realidade, uma interpretação".

Neste sentido, julgamos válido compreender o ensaio introdutório como uma prática de discurso paralelo e comentário crítico. No que concerne à função-autoria, se um locutor-editor garante a unidade da obra, há que se ter em vista que Nenbum Brasil existe é marcada por uma dispersão e se representa discursivamente como um mosaico de vozes, de textos e de perspectivas a respeito do Brasil, em meio à materialidade concreta do alentado volume que se representa como unidade, na perspectiva documental. Também, a função locutor-organizador do projeto administra a dispersão de vozes ao mesmo tempo em que discute a obra, fala da problemática evocada pelo título Nenhum Brasil existe, dialogando com um leitor cuja imagem é associada à reflexão sobre o Brasil e a uma espécie de diálogo compartilhado.

A antologia, neste caso, instaura um complexo efeito-autoria que se faz presente: a função do locutor - editor que garante à obra a concretude de antologia (livro), a do locutor-organizador, representado socialmente como um intelectual especialista que orquestra a produção e a do locutor-ensaísta colaborador, representado socialmente como um intelectual legitimado, convidado a falar sobre um assunto. Tal heterogeneidade, constitutiva da antologia como projeto, emerge na discursividade 
do ensaio introdutório, assinado por Rocha. Assim, ressoam os itens lexicais: diferentes, opostas, pluralidade, de modo que tal discurso do ensaio introdutório constrói representações de diferentes visões, de vozes, orquestradas a partir de um efeito de homogeneidade produzido pelo aparente fechamento da antologia como objeto de bordas mais ou menos estáveis.

Vale destacar que a dispersão de diferentes formações discursivas não é apagada pelo organizador; pelo contrário, ele insiste o tempo todo, na apresentação de sua obra, em evidenciar os conflitos que não deixam de constituir a própria identidade nacional. Entre diferentes vozes e perspectivas, há também um espaço de filiações a redes de sentidos que apontam para a diferença.

A fim de entender o funcionamento da heterogeneidade mostrada no texto enquanto marca de intertextualidade, vale pensar na presença do outro na cadeia discursiva, a partir das formas de heterogeneidade mostrada marcada, da ordem da enunciação, visível na materialidade linguística, como, por exemplo, o discurso direto, as palavras entre aspas; e a não marcada, da ordem do discurso, sem visibilidade, como o discurso indireto livre e a ironia.

Assim sendo, emerge, no espaço deste "discurso paralelo e crítico", como matéria-prima, o discurso literário em termos de memória do qual ecoam FDs contraditórias a respeito da ideia de identidade e nação, que participam da instauração do gesto de nomear da antologia e da formulação do próprio ensaio introdutório, a partir do fragmento extraído de Drummond "nenhum Brasil existe", uma heterogeneidade mostrada marcada. O que é chamado de introdução constitui-se em um ensaio produzido pelo organizador da obra. O ensaio é intitulado "Nenhum Brasil existe: poesia como história cultural" e também se relaciona ao fragmento do poema "Hino Nacional", da autoria de Carlos Drummond de Andrade.

Os sentidos de que o Brasil não existe é signo vazio, à espera de definições que se apresentam como uma regularidade enunciativa do ensaio assinado pelo organizador da coletânea que se representa como um locutor-especialista em literatura. Assim 
sendo, vale a pena analisar algumas marcas linguístico-discursivas recorrentes no início do ensaio introdutório que funciona como uma apresentação não somente da antologia, mas do próprio Brasil representado como vazio e inexistente.

SD (6) De fato, o autor de "Hino Nacional" parece sugerir que, em lugar de signo repleto de um sentido que reforça a si próprio, a nação seria antes um significante vaz̧io ao qual se atribui carga semântica segundo as diferentes necessidades geradas pela contingência das circunstâncias históricas. Por isso nem o Brasil, tampouco os brasileiros existem, ou melhor, somente existem através das imagens que dele construimos (p.21).

$\mathrm{SD}$ (7) “[...] a Revolução de 30 aprofundou um processo de modernização das estruturas econômicas e sociais, incluindo um ativo programa cultural cuja meta era tornar os brasileiros orgulhosos de seu país mediante a descoberta e a promoção de potencialidades até então negligenciadas. [...] O poema de Drummond parece sugerir que o Brasil oficial não passava de um artifício resultante da cuidadosa orquestração por parte dos revolucionários que tomaram o poder em 1930”. Dessa perspectiva, o paradoxo se converte numa crítica: o "Brasil oficial não coincide com o Brasil" Talvezpor isso, o Brasil inexista e ao mesmo tempo proclame sua inexistência. Em outras palavras, há um Brasil que precede o Estado e, consequentemente, não pode ser reduzido à imagem oficial (p.18).

Também, a partir dos fragmentos acima, podemos dizer que o Brasil, neste metatexto, ou seja, um texto que comenta criticamente tanto a antologia quanto o Brasil- sua história literáriocultural, é representado como artifício resultante da cuidadosa orquestração, como parte de um ativo programa cultural, ou ainda o Brasil é colocado como reconstruído a partir de diversos esforços. Tomando por base o exame dessas ressonâncias, podemos destacar a representação de Brasil como lugar de tensão de significados ou de identidades geridas pelo poder. 
Neste sentido, a intervenção intertextual, a partir de um fragmento do poema de Drummond, sugere um movimento de sentidos em que há uma tentativa de fazer sobrepor uma imagem oficial de Brasil em relação a uma imagem de Brasil, que precede o Estado, culminando assim na sua inexistência, na medida em que haveria assim um "Brasil oficial que não coincide com o Brasil.

Tal inexistência se perfaz em um movimento em que os efeitos de sentidos apontam para a multiplicidade de interpretações para o Brasil. Se o Brasil é inexistente porque o Brasil oficial sufoca o outro Brasil, podemos também dizer que o país se constitui a partir de uma identidade incompleta, cujo ponto de ancoragem está na teologia negativa, constitutiva do discurso intelectual brasileiro, denominada pelo autor do ensaio, o organizador da obra, como "arqueologia da ausência". Ressoam nestes fragmentos as expressões parafrásticas: perturbadora contradição, arqueologia da ausência, teologia negativa, melancólica descrição, participando da produção de sentidos dominantes de Brasil como lugar do problema e do vazio.

SD (8) No trabalho dos mais importantes "pensadores" do Brasil reaparece a perturbadora contradição drummondiana: seus textos desenvolvem o que já denominei de "arqueologia da ausência. Embora busquem definir a brasilidade, terminam repetindo o artifício da teologia negativa, característica de certa hermenêutica religiosa [...]. Os principais pensadores que se dedicaram à tarefa de revelar o propriamente brasileiro do Brasil terminam às voltas com uma melancólica descrição do que o país não foi- moderno, democrático, etc.- do que deixou e ser-igualitário, iluminista, etc.- do que ainda não é-país de primeiro mundo, potência mundial, etc. (p. 23)

$\mathrm{Na}$ textualidade do ensaio de apresentação da antologia, nota-se, também, a insistência nos modos de dizer explicativo a partir das marcas ou seja, dos traços da pontuação, de acréscimos livres, como por exemplo: "uns desterrados em sua terra, um hóspede alheio, a ficção adquiria significado de iniciação ao conhecimento da realidade do país". Todos esses modos de 
explicação participam da representação dominante de um país falho na constituição de uma imagem de nação.

SD (9) Desde a difusão do vocábulo, ser brasileiro é literalmente uma espécie de estrangeiro para si mesmo, um hóspede alheio- "uns desterrados em sua terra"- na formulação paradoxal e definitiva de Sérgio Buarque de Holanda. (p. 24)

SD (10) Na introdução à Formação da literatura brasileira, Antonio Candido argumenta que uma literatura como a do Brasil necessita de um contato permanente com literatura estrangeiras para não correr o risco de perder-se num inevitável provincianismo. (p. 27)

SD (11) Um Alencar ou um Domingos Olímpio eram, ao mesmo tempo, o Gilberto Freyre e o José Lins do Rego em seu tempo: a fiç̧ão adquiria significado de iniciação ao conbecimento da realidade do país. (nota de rodapé, p. 29)

Em termos de marcas de heterogeneidade mostrada, destacam-se as vozes de Candido e de Sérgio Buarque de Holanda, as quais reiteram sentidos de Brasil que não se completa, cuja literatura depende de outras ou uma representação de que a Literatura Brasileira preencheria o vazio deixado pela Filosofia e Ciências Humanas, isto é, tem-se a construção de uma representação de país falho em sua produção literário-intelectual ou na sua própria constituição como nação. Mas se o ensaio recupera e retoma esse discurso melancólico e pessimista da intelectualidade brasileira, esse ainda traz à tona, a partir de outras vozes, pela citação direta, a possibilidade de superação dessa melancolia.

SD (12) Seria interessante associar a noção de antropofagia à pesquisa de Luiz Felipe de Alencastro, como estratégia de superação ou ao menos de problematização da "teologia negativa". (p. 26)

SD (13) Intuição que Oswald de Andrade já havia arranhado com sua inteligência relâmpago e cujas conseqüências mais 
radicais ainda não soubemos enfrentar. A o contrário da teologia negativa, marcada por certa melancolia- afinal, seu propósito secreto era nada menos que desvelar a essência da nacionalidade- o gesto antropofágico, partindo da necessária presença do outro, pode transformar alegremente o tabu em totem. (p. 26)

\subsection{Organização das seções de ensaios na antologia}

Temos que compreender que, dentro da perspectiva da antologia, há dois gestos de documentação que produzem seus efeitos na formulação da obra: um relativo à seleção de textos (compilação) a serem organizados na antologia e outro relativo ao recorte, à delimitação de materiais de qualidade para compor a coletânea de textos, considerando-se, neste caso, que a funçãoautor consequentemente instaura uma função-leitor que lhe é correspondente.

No processo de constituição, formulação e circulação da obra, a antologia emerge, em termos de formulação dos sentidos, como guia seguro de história literário-cultural bastante volumoso. Neste sentido, tendo em mente os lugares nos/a partir dos quais a coleção foi formulada e circula, as instituições (as acadêmicas, ou as governamentais), a exemplo de Nenbum Brasil existe, assumem papel preponderante tanto na construção de um saber intelectual quanto no controle das obras e de textos de referência sobre o Brasil.

No meio acadêmico-intelectual, Nenbum Brasil existe dá corpo a uma memória que vem de outro lugar e põe em cena, no contexto brasileiro, um modo de circular um conjunto de textos, a partir da perspectiva do acúmulo e do critério quantitativo, o que está associado diretamente à tradição anglo-saxônica (e não à brasileira), em termos de produção antológica. Nenbum Brasil existe representase como materialização de uma memória ligada diretamente à tradição das antologias Norton, em termos de seleção de textos relativos à literatura. Mas a qualidade de ser uma obra alentada funciona, em termos de formulação e circulação, de modo bastante 
contraditório: se a antologia se projeta como possibilidade de formular e colocar muitos textos em circulação a partir de sua publicação, seu volume e extensão dificultam o processo: a obra fica fadada às estantes das bibliotecas, designada como obra de referência e sem a possibilidade de circular entre os leitores.

Nenbum Brasil existe nos leva, também, a pensar a respeito do desempenho das editoras e da própria mídia (jornais, revistas, sites na internet) que, por meio de estratégias de marketing ou de divulgação, fazem da obra um produto de consumo apetecível junto de um determinado público. Neste caso, podemos ressaltar que, em Nenhum Brasil existe, as condições de produção da coleção estão intimamente relacionadas aos percursos de formulação e circulação da obra. Seja, quando pensamos nas escolhas por temas literários e ligados à temática do estrangeiro em torno dos quais as seções de ensaios foram organizadas, bem como na perspectiva de panorama a partir da qual foram incluídos ensaios de vários autores literários.

Divididos em sete seções, os 88 ensaios em geral estão materializando uma memória de Brasil como criação de perspectivas estrangeiras e como nação/cultura marcada pelo papel decisivo da Literatura. A partir desses sentidos que vêm de outro lugar, pela memória, a antologia se constitui como arquivo que organiza textos que podem ser consultados, ou seja, documentos que produzem saberes sobre o Brasil, relacionando instituições e o próprio desenvolvimento da ciência e do conhecimento produzido pelas universidades.

Com efeito, as seções são intituladas a partir de um imaginário de Brasil (sempre) em relação ao outro estrangeiro. Nestas seções, são convocadas estas memórias relacionadas a um contato do Brasil permanente com o outro. Encaixam-se neste perfil as seções: Carta de Caminha, Intermediários culturais, Gilberto Freyre: teoria de exportação. Neste caso, o ensaio introdutório formula justamente essa representação de Brasil antropofágico.

$\mathrm{SD}$ (14) $A$ antropofagia enquanto conceito de estratégia cultural ofereceu um modelo de diálogo - o banquete antropofágico-para a interpretação. (p. 25) 
SD (15) [...] Esse é o significado mais intrigante da antropofagia, já vislumbrado por Arthur Rimbaud "Je est un autre". E é o somente através do outro que podemos conbecer (um pouco) de nós mesmos. (p. 26)

Outras seções que também dão corpo a uma memória nacional dizem respeito às partes: Literatura, Cultura, História e crítica literária. Neste caso, vale citar os fragmentos a partir dos quais, no ensaio introdutório da antologia, emerge uma representação de identidade nacional vinculada à Literatura.

SD (16) Dessa forma, o leitor pode ter uma idéia das questões e dificuldades enfrentadas pela instituição dos estudos literários no Brasil, estudos esses empenhados na busca da identidade nacional. (p. 29)

SD (17) Nas palavras de Candido diferentemente do que sucede em outros países, a literatura tem sido aqui, mais que a filosofia e as ciências humanas, o fenômeno central da vida do espirito.[...] obras literárias e ensaios interpretativos foram responsáveis por traduzir o processo histórico brasileiro em narrativas de formação do país") [...]

Por fim, a última seção Audiovisual da antologia circunscreve um espaço para este elemento- o audiovisual- na construção da identidade brasileira e na construção de narrativas nacionais. Sem perder de vista o diálogo com a Literatura, a antologia ressignifica a produção de conhecimentos sobre o país a partir de outras formas de arte e de manifestação cultural.

SD (19) [...] não é, pois, uma surpresa que, nos anos 60 do século XX, filmes tenham sido considerados instrumentos para mudanças revolucionárias. A música popular, por exemplo, segue desempenhando um papel significativo na definição de identidades brasileiras. Isto para não mencionar as redes de televisão, que são o mais forte elemento de coesão na sociedade brasileira contemporânea. (p. 30) 


\section{Gesto Final}

Duas questões relativas à memória do dizer merecem destaque. Primeiro, é válido destacar que as representações de sentidos dominantes construídas no caso de Nenhum Brasil existe coloca em cena pontos de equivocidade no/do jogo do texto e da memória a partir de sentidos contraditórios que significam o Brasil como ausente/presente, vazio/permeado pelo outro.

Segundo, é possível dizer que falar do Brasil, nesta coleção, envolve múltiplas visões, diversas perspectivas que, numa espécie de espaço discursivo de debate e embate de vozes, constituem um exemplar de um processo discursivo mais amplo em que se esboça a ensaística nacional. Uma obra que se projeta justamente com a pretensão de ser uma referência a estudantes.

Com efeito, em termos de constituição de um imaginário de leitura, pela trilha intelectual, que perpassa a ensaística brasileira, a coleção produz representações que caracterizam o espaço de leitura, assim como o do Brasil, como lugar da falta e da necessidade de crítica.

Mas se a crítica é tão necessária, há que se levar em conta o caráter contraditório dessa obra analisada, em termos de formulação e circulação. Com efeito, Nenbum Brasil existe, embora se represente como guia seguro ou obra indispensável, buscando preencher certa lacuna em termos de práticas de leitura de ensaios sobre cultura e literatura, a obra não tem seu acesso facilitado ou uma circulação mais significativa, considerando-se outros espaços que não o acadêmico.

A antologia de ensaios aqui analisada é uma obra que circula em contextos muito restritos: ou se encontra listada em bibliografias de muitos cursos de graduação ou Pós-Graduação em História, em Ciências Sociais, Estudos Culturais e Antropológicos, Letras, Literatura, espalhados pelo Brasil, ou tal obra compõe os livros exigidos pelos Exames e Concursos do Instituto Rio Branco.

Neste caso, a obra, como projeto, embora pretenda proporcionar a reflexão e a leitura sobre o Brasil, por sua vez, na sua realização efetiva, está ainda circunscrita a espaços limitados e 
constitui referências reservadas a uma elite de leitores. Assim, nem o estudante de Ensino médio, tampouco o universitário terão acesso a seus bons ensaios e a esse rico material sobre o Brasil.

Nenhum Brasil existe nos leva a pensar o papel desempenhado pelos intelectuais e pela produção acadêmica no Brasil em termos práticos. Ainda que a obra realmente seja constituída por uma gama de bons textos, assinados por diversos autores, entretanto, por conta de sua extensão e volume, semelhante a uma enciclopédia ou dicionário, tem sua circulação prejudicada (é tachada como obra de referência, ou seja, de circulação interna) e fica restrita ao uso somente no interior das bibliotecas. Além disso, infelizmente, a obra está produzindo efeitos em leitores específicos e faz parte das estantes de um público seleto no Brasil.

Enfim, contraditoriamente, a antologia é fantasma e lacuna. E, se nem a obra ou o Brasil existem, também podemos pensar que para os leitores escolares, seja os do ensino médio, seja os da universidade, a obra realmente ainda não existe. Neste caso, precisamos pensar a relevância de divulgação de obras deste tipo para então abrirmos espaços para que, de fato, seja promovida a leitura deste tipo de material entre estudantes de Graduação ou Ensino Médio, levando os sujeitos a problematizarem os temas controversos e os dilemas nacionais.

\section{Referências}

FOUCAULT, Michel. A Arqueologia do Saber. Trad. Luiz Baeta Neves. Rio de Janeiro: Forense-Universitária, 1987 [1969].

GENETTE, Gérard. Palimpsests: Literature in the Second Degree. Trad. London: University of Nebraska Press, 1997.

GUIMARÃES, E duardo. Sentido e acontecimento. Um estudo do nome próprio. Campinas: Unicamp, 2000. [mimeo]

ORLANDI, Eni. Interpretação. Autoria, leitura e efeitos do trabalho simbólico. São Paulo: Vozes, 1986. 
A linguagem e seu funcionamento. 2. ed. rev. e aum. As formas do discurso. Campinas: Pontes, 1987.

Análise do discurso: princípios e procedimentos. Campinas: Pontes, 1999.

PÊCHEUX, Michel. Semântica e Discurso. Uma crítica à afirmação do óbvio. Trad. Eni P. de Orlandi et al. Campinas: Editora da UNICAMP, 1988.

Análise automática do discurso (AAD- 69) e Análise automática do Discurso: três épocas. In: GADET, Françoise; HAK, Tony. (Orgs.). Por uma análise automática do discurso. Ed. Unicamp: Campinas, 1990 [1969].

PÊCHEUX, Michel. O papel da memória. In: ACHARD, Pierre et al. Papel da memória. Trad. e introd. José Horta Nunes. Campinas: Pontes, 1999. p. 49-57.

SERRANI, Silvana. A linguagem na pesquisa sociocultural. Um estudo da repetição na discursividade. Campinas: Editora da UNICAMP, 1983.

Identidade e representação do Brasil em antologias poéticas bilíngües. In: CORACINI, Maria José; GRIGOLETO, Marisa; Magalhães, Izabel. Práticas identitárias em Lingüística Aplicada. São Paulo: Parábola, 2006.

ZOPPI-FONTANA, Mônica Graciela. En los márgenes del texto, intervalos de sentidos en movimiento. Páginas de Guarda Revista de lenguaje, edición y cultura escrita, v. 4, p. 11-39, 2007. 